\title{
A Small-Scale Setup for Algal Toxicity Testing of Nanomaterials and Other Difficult Substances
}

Skjolding, Lars Michael; Kruse, Susanne; Sørensen, Sara Nørgaard; Hjorth, Rune; Baun, Anders

Published in:

Journal of Visualized Experiments

Link to article, DOI:

$10.3791 / 61209$

Publication date:

2020

Document Version

Peer reviewed version

Link back to DTU Orbit

Citation (APA):

Skjolding, L. M., Kruse, S., Sørensen, S. N., Hjorth, R., \& Baun, A. (2020). A Small-Scale Setup for Algal Toxicity Testing of Nanomaterials and Other Difficult Substances. Journal of Visualized Experiments, [e61209]. https://doi.org/10.3791/61209

\section{General rights}

Copyright and moral rights for the publications made accessible in the public portal are retained by the authors and/or other copyright owners and it is a condition of accessing publications that users recognise and abide by the legal requirements associated with these rights.

- Users may download and print one copy of any publication from the public portal for the purpose of private study or research.

- You may not further distribute the material or use it for any profit-making activity or commercial gain

- You may freely distribute the URL identifying the publication in the public portal 
TITLE:

A Small-Scale Setup for Algal Toxicity Testing of Nanomaterials and Other Difficult Substances

\author{
AUTHORS AND AFFILIATIONS: \\ Lars Michael Skjolding, Susanne Kruse, Sara Nørgaard Sørensen, Rune Hjorth, Anders Baun \\ Department of Environmental Engineering, Technical University of Denmark, Kongens Lyngby, \\ Denmark
}

Email Addresses of co-authors:

Susanne Kruse (sukr@env.dtu.dk)

Sara Nørgaard Sørensen (sans@env.dtu.dk)

Rune Hjorth_ (ruhjo@mst.dk)

Anders Baun (abau@env.dtu.dk)

Corresponding Author:

Lars Michael Skjolding (lams@env.dtu.dk)

\title{
KEYWORDS:
}

ecotoxicity, growth inhibition, colored substances, nanomaterials, Raphidocelis subcapitata, OECD 201, ISO 8692, LEVITATT

\section{SUMMARY:}

We demonstrate algal toxicity testing for difficult substances (e.g., colored substances or nanomaterials) using a setup illuminated vertically with an LED.

\section{LONG ABSTRACT:}

Ecotoxicity data is a requirement for pre- and post-market registration of chemicals by European and international regulations (e.g., REACH). The algal toxicity test is frequently used in regulatory risk assessment of chemicals. In order to achieve high reliability and reproducibility the development of standardized guidelines is vital. For algal toxicity testing, the guidelines require stable and uniform conditions of parameters such as $\mathrm{pH}$, temperature, carbon dioxide levels and light intensity. Nanomaterials and other so-called difficult substances can interfere with light causing a large variation in results obtained hampering their regulatory acceptance. To address these challenges, we have developed LEVITATT (LED Vertical Illumination Table for Algal Toxicity Tests). The setup utilizes LED illumination from below allowing for a homogenous light distribution and temperature control while also minimizing intra-sample shading. The setup optimizes the sample volume for biomass quantification and does at the same time ensure a sufficient influx of $\mathrm{CO}_{2}$ to support exponential growth of the algae. Additionally, the material of the test containers can be tailored to minimize adsorption and volatilization. When testing colored substances or particle suspensions, the use of LED lights also allows for increasing the light intensity without additional heat generation. The compact design and minimal equipment requirements increase the possibilities for implementation of the LEVITATT in a wide range of laboratories. While compliant with standardized ISO and OECD guidelines for algal toxicity 
testing, LEVITATT also showed a lower inter-sample variability for two reference substances (3,5Dicholorophenol and $\left.\mathrm{K}_{2} \mathrm{Cr}_{2} \mathrm{O}_{7}\right)$ and three nanomaterials $\left(\mathrm{ZnO}, \mathrm{CeO}_{2}\right.$, and $\mathrm{BaSO}_{4}$ ) compared to Erlenmeyer flasks and microtiter plates.

\section{INTRODUCTION:}

The algal toxicity test is one of only three mandatory tests used to generate the ecotoxicity data required for pre- and post-market registration of chemicals by European and international regulations (e.g., $\mathrm{REACH}^{1}$ and TSCA (USA)). For this purpose, standardized algal test guidelines have been developed by international organizations (e.g., ISO and OECD). These testing standards and guidelines prescribe ideal test conditions in terms of $\mathrm{pH}$, temperature, carbon dioxide levels and light intensity. However, maintaining stable test conditions during algal testing is in practice difficult and the results suffer from problems with reproducibility and reliability for a range of chemical substances and nanomaterials (often referred to as "difficult substances") ${ }^{2}$. Most of the existing algal toxicity testing setups operate with relatively large volumes $(100-250 \mathrm{~mL})$ situated on an orbital shaker inside an incubator. Such a setup limits the number of test concentrations and replicates achievable and high volumes of algal culture and test material. Additionally, these setups rarely have a uniform light field and reliable lighting conditions are furthermore difficult to obtain in large flasks, partly as light intensity decreases exponentially the further the light travels and partly due to the flask geometry. Alternative setups comprise plastic microtiter ${ }^{3}$ plates containing small sample volumes that do not allow for adequate sampling volumes to measure $\mathrm{pH}$, additional biomass measurements, pigment extraction or other analyses requiring destructive sampling. One particular challenge using existing setups for algal toxicity testing of nanomaterials and substances forming colored suspensions is the interference or blocking of the light available to the algal cells, often referred to as "shading" 4,5 . Shading may occur within vials by the test material and/or interactions between the test material and the algal cells, or shading can occur between vials, due to their positioning relative to each other and the light source.

The method is based on the small-scale algal toxicity test setup introduced by Arensberg et al. ${ }^{6}$ that allows for testing in compliance with standards such as OECD $201^{7}$, and ISO $8692^{8}$. The method is further optimized to address the limitations stated above by: 1) utilizing the LED light technology to ensure uniform light conditions with minimal heat generation, 2) providing adequate sample volume for chemical/biological analysis while maintaining constant $\mathrm{pH}, \mathrm{CO}_{2}$ levels, and 3) enabling the use of versatile test container material for testing of volatile substances or substances with a high sorption potential.

\section{PROTOCOL:}

81

\section{Description of the LEVITATT setup}

1.1. Use $20 \mathrm{~mL}$ scintillation glass vials (Figure 1, insert 1) allowing light penetration. Alternatively, light penetrable plastic vials can be used. Quantify the light intensity using a photometer.

1.2. Use at least a $4 \mathrm{~mL}$ test suspension at the beginning of the test to allow for quantification 
of biomass and for characterization/quantification of nanomaterials during and after incubation (Figure 1, insert 2).

1.3. Fit the $20 \mathrm{~mL}$ scintillation vials with a cap (Figure 1, insert 3) where a small hole is drilled (approximately $1 \mathrm{~mm}$ in diameter) to allow for $\mathrm{CO}_{2}$ exchange with the atmosphere. This exchange is crucial to ensure stable $\mathrm{pH}$ and $\mathrm{CO}_{2}$ levels during testing.

1.4. For volatile substances, use an air-tight Teflon coated cap to allow for $\mathrm{CO}_{2}$ enriching of the headspace using a syringe ${ }^{9}$ or completely closed flasks with no gas phase in which $\mathrm{CO}_{2}$ is maintained in solution by an enriched sodium bicarbonate $\left(\mathrm{NaHCO}_{3}\right)$ buffer system ${ }^{10}$.

1.5. Fasten the vials with clamps mounted on the exterior casing (Figure 1, insert 4).

1.6. Use an LED light source located below the test vials (Figure 1, insert 5) providing a uniform fluorescent illumination of "cool-white" or "daylight" type and a light intensity in the range 60$120 \mu \mathrm{E} \cdot \mathrm{m}^{-2} \cdot \mathrm{s}^{-1}$ measured in the photosynthetically effective wavelength range of $400 \mathrm{~nm}$ to 700 $\mathrm{nm}$. The setup employs adjustable light intensity in the range $5-160 \mu \mathrm{E} \cdot \mathrm{m}^{-2} \cdot \mathrm{s}^{-1}$ by fitting a light dimmer to the source. This allows for testing at higher and lower light intensities.

1.7. Mount the setup on an orbital shaker to agitate samples throughout the duration of the test. This keeps the cells in free suspension and facilitates $\mathrm{CO}_{2}$ mass transfer from air to water (Figure 1, insert 6).

1.8. Place the setup in a temperature-controlled room or a thermostatic cabinet to maintain stable temperatures throughout testing (Figure 1, insert 7).

[Place Figure 1 here]

\section{Preparation of algal growth medium}

2.1. The ISO 8692 algal growth medium consists of four different stock solutions. Weigh out the appropriate amount of salts and dilute in ultrapure water according to Table 1.

\section{[Place Table 1 here]}

NOTE: $\mathrm{H}_{3} \mathrm{BO}_{3}$ can be dissolved by adding $0.1 \mathrm{M} \mathrm{NaOH}$. EDTA should be removed when testing metals, to avoid complexation with metal ions. Sterilize the stock solutions by membrane filtration (mean pore diameter $0.2 \mu \mathrm{m}$ ) or by autoclaving $\left(120^{\circ} \mathrm{C}, 15 \mathrm{~min}\right.$ ). Do no autoclave stock solutions 2 and 4 , but sterilize them by membrane filtration. Store the solutions in the dark at 4 ${ }^{\circ} \mathrm{C}$.

2.2. To produce $1 \mathrm{~L}$ of algal growth medium, transfer $500 \mathrm{~mL}$ sterilized ultrapure water into a $1 \mathrm{~L}$ sterilized volumetric flask and add $10 \mathrm{~mL}$ of stock solution 1: Macronutrients, $1 \mathrm{~mL}$ of stock solution 2: Fe-EDTA, $1 \mathrm{~mL}$ of stock solution 3: Trace elements, and $1 \mathrm{~mL}$ of stock solution 4 : 
133

134

135

136

137

138

139

140

141

142

143

144

145

146

147

148

149

150

151

152

153

154

155

156

157

158

159

160

161

162

163

164

165

166

167

168

169

170

171

172

173

174

175

176

$\mathrm{NaHCO}_{3}$.

2.3. Fill up to $1 \mathrm{~L}$ with sterilized ultrapure water, stopper the flask and shake thoroughly to homogenize the algal growth medium.

2.4. Equilibrate the solution before use by leaving it overnight in contact with air or by bubbling with sterile, filtered air for $30 \mathrm{~min}$. After equilibration, adjust the $\mathrm{pH}$, if necessary, to $\mathrm{pH}$ $8.1 \pm 0.2$, with either $1 \mathrm{M} \mathrm{HCl}$ or $1 \mathrm{M} \mathrm{NaOH}$.

\section{Setting up the algal test}

NOTE: A flow diagram of the algal test procedure is shown in Figure $\mathbf{2}$.

[Place Figure 2 here]

3.1. Prepare a stock solution of the test compound at the desired highest test concentration in the algal growth medium prepared according to step 2. For preparation of stock solutions/suspensions, follow OECD 201 (for soluble compounds) or OECD 318 (for nanomaterials).

3.2. Measure the $\mathrm{pH}$ in the stock solution. If it deviates more than one unit from the algal growth medium, adjust the $\mathrm{pH}$ to 8 with either $1 \mathrm{M} \mathrm{HCl}$ or $1 \mathrm{M} \mathrm{NaOH}$.

3.3. Calculate the inoculum volume needed to reach a final cell concentration of $1 \times 10^{4}$ cells $/ \mathrm{mL}$ in a $25 \mathrm{~mL}$ test solution.

NOTE: The inoculum should come from a culture of uncontaminated exponentially growing Raphidocelis subcapitata grown using the LEVITATT setup.

3.4. Calculate the amount of stock solution to add to each $25 \mathrm{~mL}$ volumetric flask to obtain the desired test concentrations. The factor between each concentration should not exceed 3.2.

3.5. Mark one $25 \mathrm{~mL}$ volumetric flask for each chosen concentration and an additional $25 \mathrm{~mL}$ volumetric flask marked control.

3.6. Add the amount of stock solution of the test compound needed to reach the desired concentrations to the $25 \mathrm{~mL}$ volumetric flask. Do not add stock solution to the control.

3.7. Add the medium to each $25 \mathrm{~mL}$ volumetric flask to reach a volume of approximately 20 $\mathrm{mL}$.

3.8. Add the volume of inoculum calculated in step 3.3 to each $25 \mathrm{~mL}$ volumetric flask. Add the medium to each $25 \mathrm{~mL}$ volumetric flask to a final total volume of $25 \mathrm{~mL}$. 
3.9. Stopper the flasks and mix thoroughly by turning the flasks two times vertically.

3.10. Transfer $0.4 \mathrm{~mL}$ from each flask into individual screw cap vials and add $1.6 \mathrm{~mL}$ of acetone (saturated with $\mathrm{MgCO}_{3}$ ): one sample for each test concentration and the control. Close the lids tightly and store in the dark at room temperature until fluorescence measurements (section 4).

3.11. Pipet $4 \mathrm{~mL}$ of each test solution into $20 \mathrm{~mL}$ scintillation vials (3 replicates per concentration and 5 replicates for the control). Screw lids on the scintillation vials. Remember that the lids must have a drilled hole (approximately $1 \mathrm{~mm}$ in diameter) to allow for $\mathrm{CO}_{2}$ exchange.

3.12. After $24 \mathrm{~h}, 48 \mathrm{~h}$, and $72 \mathrm{~h}$, pipet $0.4 \mathrm{~mL}$ from each vial into screw cap vials and add $1.6 \mathrm{~mL}$ of acetone (saturated with $\mathrm{MgCO}_{3}$ ). Close the lids tightly and store in the dark at room temperature until fluorescence measurements (section 4).

3.13. After the last sample is taken at $72 \mathrm{~h}$, gently pool the three replicates for a given concentration in one vial and measure the $\mathrm{pH}$. Repeat for all concentrations and the control. The $\mathrm{pH}$ should not deviate more than 1.5 units from the initial pH for any of the samples measured.

3.14. Discharge the remaining liquids into a waste container following your institutional rules and regulations.

\section{Analyzing algal test samples}

4.1. Use a fluorescence spectrophotometer to measure the algal biomass (here expressed as chlorophyll A). The peak emission for chlorophyll A is $420 \mathrm{~nm}$ for the excitation wavelength and $671 \mathrm{~nm}$ for the emission wavelength.

4.2. Measure the fluorescence of each individual sample three times and calculate the average value for each sample.

4.3. Use equation 1 to calculate the growth rate. The measured fluorescence (relative units) can be used directly as the biomass parameter in equation 1 .

Equation 1: $\quad \mu=\left(\ln \mathrm{N}_{\mathrm{t}}-\ln \mathrm{N}_{0}\right) / \mathrm{t}$ where $\mu$ is the growth rate $\left(d^{-1}\right), N_{0}$ is the initial biomass, $N_{t}$ is the biomass at time $t$, and $t$ is the length of the test period (d). Note, $N_{0}$ and $N_{t}$ should be expressed in the same unit.

4.4. Use a statistical software to fit a non-linear regression curve (e.g., a log-logistic or Weibull function) to the growth rate data to obtain effective concentration values at $10 \%, 20 \%$, and $50 \%$ inhibition. In the supplementary information an example of code for fitting in the statistical software $R$ using the DRC package ${ }^{11}$ is given.

\section{REPRESENTATIVE RESULTS:}

An initial test with a reference substance is carried out to determine the sensitivity of the algal 
strain. Reference substances regularly used for $R$. subcapitata are potassium dichromate and 3,5Dichlorphenol ${ }^{7,8}$. Figure $\mathbf{3}$ and Table $\mathbf{2}$ show a representative result of an algal test including curve fitting and statistical outputs when the DRC package in $\mathrm{R}$ is applied to the growth rates.

A successful test will have growth rates above $0.9 \mathrm{~d}^{-1}$ to comply with the OECD guideline and 1.5 $\mathrm{d}^{-1}$ to comply with ISO 8692 guideline and should contain at least one concentration between $0 \%$ and $100 \%$ inhibition. Low growth rates may occur as a result of various issues such as bacterial contamination or inoculum not being in the exponential growth phase at the beginning of the test. Microscopic investigation of the replicates should only show uniform sickle-shaped green algae ( $R$. subcapitata) with dimensions of approximately $2 \mu \mathrm{m}$ width and $8 \mu \mathrm{m}$ length. If a single replicate is contaminated, it can be omitted and the analysis can be carried out without this data. However, if multiple replicates are contaminated, repeat the experiment with uncontaminated exponentially growing inoculum. To evaluate whether the inoculum was in the exponential growth phase at the beginning of the test, calculate the growth rate of the control replicates at $24 \mathrm{~h}$ intervals and use only the time interval at which the algal growth of the control is exponential for statistical analysis.

To test the robustness of the setup, a toxicity test using two reference substances $\left(\mathrm{K}_{2} \mathrm{Cr}_{2} \mathrm{O}_{7}\right.$ and 3,5-Dichlorophenol) and three nanomaterials was repeated three times (3,5-Dichlorophenol, $\mathrm{BaSO}_{4}$ nanoparticles (NM-220), and $\mathrm{ZnO}$ nanoparticles (NM-111)) and four times $\left(\mathrm{K}_{2} \mathrm{Cr}_{2} \mathrm{O}_{7}\right.$ and $\mathrm{CeO}_{2}$ nanoparticles (NM-212)). The results showed a coefficient of variation of the $\mathrm{EC}_{50}$-values between $11 \%$ and $39 \%$, with the lowest coefficient of variation observed for ZnO nanoparticles (NM-111) and the highest coefficient of variation for $\mathrm{CeO}_{2}$ nanoparticles (NM-212) (Table 3).

[Place Table 3 here]

FIGURE AND TABLE LEGENDS:

Figure 1: Picture of LED Vertical Illumination Table for Algal Toxicity Tests (LEVITATT). 1) 20 $\mathrm{mL}$ glass scintillation vials for incubation, 2) $4 \mathrm{~mL}$ sample for analysis, 3) lid with drilled hole for $\mathrm{CO}_{2}$ exchange, 4) casing for defined light conditions, 5) LED light source located in the center of the casing, 6) orbital shaker for agitation during the experiment, and 7) a thermostatic cabinet.

\section{Figure 2: Flow diagram of the algal test setup.}

Figure 3: Representative concentration-response curve for $72 \mathrm{~h}$ exposure of a chemical compound to algae ( $\boldsymbol{R}$. subcapitata). The solid line represents the log-logistic fit and the shaded area is the $95 \%$ confidence interval for the fit. The open circles represent the calculated growth rate for each replicate.

Table 1: Concentrations of nutrients in stock solutions for algal growth medium

Table 2: Representative effective concentrations for $10 \%, 20 \%$, and $50 \%$ inhibition of growth rate for a chemical compound using algae ( $R$. subcapitata). The value in brackets represents the 
$95 \%$ confidence interval of a log-logistic fitting.

Table 3: Results of an internal laboratory toxicity test with $R$. subcapitata exposed for $72 \mathrm{~h}$ to two reference substances and three nanomaterials from the JRC repository

\section{DISCUSSION:}

Phytoplankton converts solar energy and carbon dioxide to organic matter and thus holds a pivotal role in the aquatic ecosystem. For this reason, algal growth rate inhibition tests are included as one of three mandatory aquatic toxicity tests required for regulatory risk assessment of chemicals. The ability to perform a reliable and reproducible algal toxicity test is key in this regard. Test setups using Erlenmeyer flasks introduces a range of variabilities and inconveniences as described in the introduction. To circumvent this issue, microtiter plates have been proposed ${ }^{3}$. While the microtiter plates minimize the volume and space required for testing, concerns have been raised in literature with regard to the compliance of such setups with the test validity criteria of test guidelines ${ }^{6}$. For example, significant loss of semivolatile chemicals as well as crossover to other wells in microtiter plates at $37^{\circ} \mathrm{C}$ in cellular growth media (DMEM GluteMAX, OptiMEM, and Hams F12 GlutaMAX) was recently demonstrated by Birch et al. ${ }^{12}$. Testing of volatile substances may be successfully conducted with the LEVITATT setup using 1) closed vials with $\mathrm{CO}_{2}$ enriched headspace ${ }^{9}, 2$ ) directly dosing the volatile compound through the headspace ${ }^{13}$ or in a filled test via ${ }^{10}$. In terms of space requirements, LEVITATT provides a test setup that fills the gap between microtiter plates and Erlenmeyer flask setups while still providing benefits from both setups, e.g., maintaining a concise and compact test environment and sufficient test volume for destructive sampling (e.g., for characterization of nanomaterials during the test).

The inter-sample variability for the LEVITATT test system ranged from 3.4\% (3,5-Dichlorophenol and $\mathrm{ZnO} N \mathrm{NP})$ to $5.6 \%\left(\mathrm{BaSO}_{4} \mathrm{NP}\right)$. This is within the requirement of coefficient of variation of average growth in replicate control cultures of $15 \%$ indicated by the OECD 201 guideline ${ }^{7}$ (for the LEVITATT inter-sample variability all exposures were also included).

The reproducibility with regards to $\mathrm{EC}_{50}$-values of the test setup for the reference substances showed a coefficient of variance of $13 \%$ for $\mathrm{K}_{2} \mathrm{Cr}_{2} \mathrm{O}_{7}(n=4)$ and $21 \%$ for 3,5-Dichlorophenol $(n=$ 3). This is comparable to tests carried out with conventional $250 \mathrm{~mL}$ Erlenmeyer flask bioassays for the reference substance $\mathrm{K}_{2} \mathrm{Cr}_{2} \mathrm{O}_{7}$ showing $16.8 \%^{14}$ and $25.4 \%{ }^{15}$ coefficient of variation for $\mathrm{EC}_{50}$-values. Microtiter plates have shown lower variation coefficient for some reference substances (e.g., $\mathrm{K}_{2} \mathrm{Cr}_{2} \mathrm{O}_{7}\left(9 \%{ }^{14,15}\right)$, while higher coefficients of variation have been observed for phenol $\left(34.9 \%{ }^{16}\right)$ and Dichlorophenol $\left(38 \%{ }^{17}\right)$. Limited information is available with regard to reproducibility of studies with nanomaterials. However, comparing the inter-sample coefficient of variation for ZnO NPs using the LEVITATT system (3.4\%) with microtiter plates $\left(67 \%{ }^{18}\right.$ ) or Erlenmeyer flasks $\left(13 \%{ }^{19}\right.$ and $\left.35 \%{ }^{20}\right)$ it has less variation. To further test the robustness of the LEVITATT system, a round-robin study of two test materials (one reference substance and one difficult to test substance) have been initiated.

Maintaining an uncontaminated algal culture can be difficult if not handled in sterile conditions. Exponential algal growth is a key prerequisite for performing guideline algal testing. Measuring 
the growth at multiple time points (e.g., 24 h, 48 h, 72 h) can identify whether exponential growth is occurring throughout the test period. Fluctuations in temperature and $\mathrm{pH}$ can influence the algal growth; thus, these parameters must be stable throughout the test period. In small volumes of test sample, fluctuations in temperature and $\mathrm{pH}$ occur more rapidly compared to larger volumes and the practical issues of measuring these parameters are increasingly difficult with decreasing test volume. Parameters such as $\mathrm{pH}$ and temperature using $4 \mathrm{~mL}$ test volume was stable throughout a $72 \mathrm{~h}$ testing period in the LEVITATT both in a temperature-controlled room at $20^{\circ} \mathrm{C} \pm 2{ }^{\circ} \mathrm{C}$ and in an incubator at similar conditions.

Analytical methods for quantification of algal growth are many: cell counting in a haemocytometer, coulter counter, or fluorescence of pigment extracts. For difficult substances, considerations should be made with regard to the most suitable method for biomass quantification. For metal oxide nanoparticles, fluorescence of pigment extracts has been found to perform best due to interference of agglomerates when counting algae by haemocytometer or coulter counter ${ }^{21}$. In contrast, Farkas and Booth ${ }^{22}$ found that quantification of biomass by fluorescence was not a suitable method for ecotoxicity testing of carbon-based nanomaterials due to autofluorescence and absorbance of pigments to the nanomaterials. For colored substances, there may also be interference of the color with the fluorescence emission signal, thus, requiring additional controls or dilution to a level where this interference is negligible.

In the guidance document for aquatic toxicity testing of difficult substances ${ }^{2}$, one of the recommendations for testing colored materials is to increase the light intensity. Similarly, increased light intensity has been mentioned to circumvent shading issues when testing nanomaterials ${ }^{23,24}$. However, such modifications are often associated with increased temperatures, thus, requiring additional cooling or ventilation of the samples. In the LEVITATT setup, this is solved using LED light that produces little heat compared to conventional light bulbs or fluorescent tubes. Additionally, choosing an LED with a sufficiently high light intensity output and the installation of a dimmer allow for increasing the light intensity to test colored substances or nanomaterials and regular chemicals without altering the overall setup between tests. Furthermore, the placement of the light source below the samples and in separate casings allows for a consistent and homogenous light field.

In conclusion, the LEVITATT provides a compact platform for algal toxicity testing of regular chemicals compliant with international standardized guidelines. Furthermore, the setup provides a robust platform for testing of difficult substances that interfere with the passage of light toward the algal, e.g., nanomaterials.

\section{ACKNOWLEDGMENTS:}

This research was funded by PATROLS - Advanced Tools for NanoSafety Testing, Grant agreement 760813 under Horizon 2020 research and innovation program.

\section{DISCLOSURES:}


353 1. European Chemicals Agency, Guidance on Registration. Helsinki, Finland (2016).

$3542 . \quad$ Organisation for Economic Cooperation and Development, Guidance Document on 355 Aquatic Toxicity Testing of Difficult Substances and Mixtures (2019).

$356 \quad 3 . \quad$ Blaise, C., Legault, R., Bermingham, N., Van Coillie, R., Vasseur, P. A simple microplate 357 algal assay technique for aquatic toxicity assessment. Toxicity Assessment. 1 (3), 261-281 (1986).

358 4. Hjorth, R., Sorensen, S. N., Olsson, M. E., Baun, A., Hartmann, N. B. A certain shade of 359 green: can algal pigments reveal shading effects of nanoparticles? Integrated Environmental 360 Assessment and Management. 12 (1), 200-202 (2016).

3615 . Chen, F. et al. Algae response to engineered nanoparticles: current understanding $\{$, 362 mechanisms and implications. Environmental Science: Nano. 6 (4), 1026-1042 (2019).

363 6. Arensberg, P., Hemmingsen, V. H., Nyholm, N. A miniscale algal toxicity test. 364 Chemosphere. 30 (11), 2103-2115 (1995).

365 7. Organisation for Economic Cooperation and Development, Test No. 201: Freshwater Alga 366 and Cyanobacteria, Growth Inhibition Test (2011).

367 8. International Organization for Standardization (ISO), Water Quality - Fresh Water Algal Growth Inhibition Test with Unicellular Green Algae (2012).

9. Halling-Sørensen, B., Nyhohn, N., Baun, A. Algal toxicity tests with volatile and hazardous compounds in air-tight test flasks with CO2 enriched headspace. Chemosphere. 32 (8), 15131526 (1996).

10. Mayer, P., Nyholm, N., Verbruggen, E. M. J., Hermens, J. L. M., Tolls, J. Algal growth inhibition test in filled, closed bottles for volatile and sorptive materials. Environmental Toxicology and Chemistry. 19 (10), 2551-2556 (2000).

11. Ritz, C., Baty, F., Streibig, J. C., Gerhard, D. Dose-response analysis using R. PloS One. 10 (12), e0146021-e0146021 (2015).

12. Birch, H., Kramer, N. I., Mayer, P. Time-resolved freely dissolved concentrations of semivolatile and hydrophobic test chemicals in in vitro assays-measuring high losses and crossover by headspace solid-phase microextraction. Chemical Research in Toxicology. 32 (9), 1780-1790 (2019).

381 13. Trac, L. N., Schmidt, S. N., Mayer, P. Headspace passive dosing of volatile hydrophobic 382 chemicals - Aquatic toxicity testing exactly at the saturation level. Chemosphere. 211, 694-700 383 (2018).

384 14. Eisentraeger, A., Dott, W., Klein, J., Hahn, S. Comparative studies on algal toxicity testing using fluorometric microplate and Erlenmeyer flask growth-inhibition assays. Ecotoxicology and

387 15. Paixao, S. M., Silva, L., Fernandes, A., O’Rourke, K., Mendonca, E., Picado, A. Performance of a miniaturized algal bioassay in phytotoxicity screening. Ecotoxicology. 17 (3), 165-171 (2008). 16. Thellen, C., Blaise, C., Roy, Y., Hickey, C. Round-robin testing with the selenastrum-capricornutum microplate toxicity assay. Hydrobiologia. 188, 259-268 (1989). toxicity assay for riverine periphytic algal species. Ecotoxicology and Environmental Safety. 94, 37-44 (2013).

394 18. Lee, W.-M., An, Y.-J. Effects of zinc oxide and titanium dioxide nanoparticles on green 395 algae under visible, UVA, and UVB irradiations: no evidence of enhanced algal toxicity under UV 
pre-irradiation. Chemosphere. 91 (4), 536-544 (2013).

19. Samei, M., Sarrafzadeh, M.-H., Faramarzi, M. A. The impact of morphology and size of zinc

398 oxide nanoparticles on its toxicity to the freshwater microalga, Raphidocelis subcapitata.

399 Environmental Science and Pollution Research. 26 (3), 2409-2420 (2019).

400 20. Neale, P. A., Jaemting, A. K., O'Malley, E., Herrmann, J., Escher, B. I. Behaviour of titanium

401 dioxide and zinc oxide nanoparticles in the presence of wastewater-derived organic matter and

402 implications for algal toxicity. Environmental Science: Nano. 2 (1), 86-93 (2015).

403 21. Hartmann, N. B. et al. The challenges of testing metal and metal oxide nanoparticles in 404 algal bioassays: titanium dioxide and gold nanoparticles as case studies. Nanotoxicology. 7 (6), 405 1082-1094 (2013).

406 22. Farkas, J., Booth, A. M. Are fluorescence-based chlorophyll quantification methods 407 suitable for algae toxicity assessment of carbon nanomaterials? Nanotoxicology. 11 (4), 569-577 408 (2017).

409 23. Handy, R. D. et al. Practical considerations for conducting ecotoxicity test methods with 410 manufactured nanomaterials: what have we learnt so far? Ecotoxicology. 21 (4), 933-972 (2012). 411 24. Handy, R. D. et al. Ecotoxicity test methods for engineered nanomaterials: practical 412 experiences and recommendations from the bench. Environmental Toxicology and Chemistry. 31 413 (1), 15-31 (2012). 